\title{
EL DERECHO INTERNACIONAL Y SU RELEVANCIA EN EL SISTEMA JURÍDICO MEXICANO. UNA PERSPECTIVA JURISPRUDENCIAL*
}

\author{
Javier DONDÉ MATUTE**
}

RESUMEN: Este artículo tiene por propósito exponer y analizar los criterios jurisprudenciales más innovadores de la Suprema Corte de Justicia de la Nación y los tribunales colegiados de circuito de México relacionados con el derecho internacional para establecer el grado de integración con los criterios judiciales.

ABSTRACT: The purpose of this article is to expose and analyze the most innovative criteria held by the Supreme Court and Circuit Courts of Mexico related to International Law in order to establish the level of integration through judicial precedent.

RÉSUMÉ: Cet article a l'objectif de faire une exposition et d'analyser les critères jurisprudentielles plus innovateurs de la Court Suprême de Justice et les Tribunaux de Circuit du Mexique lies avec le droit international pour établir le grade d'intégration avec les critères judicieux.

* Artículo recibido el 5 de junio de 2008 y aceptado para su publicación el 18 de agosto de 2008.

** Doctor en derecho penal internacional y derecho penal comparado por la Universidad de Aberdeen (Escocia, Reino Unido); profesor e investigador en el Instituto Nacional de Ciencias Penales (Inacipe). 
SUMARIO: I. Introducción. II. Breves consideraciones teóricas. III. Suprema Corte de Justicia de la Nación. IV. Tribunales colegiados de circuito. V. Reflexiones finales y acotaciones adicionales.

\section{INTRODUCCIÓN}

El objetivo de este trabajo es analizar el papel que ha jugado el derecho internacional en la argumentación jurídica de la Suprema Corte de Justicia de la Nación (SCJN) y de los tribunales colegiados de circuito (TCC). No se trata de estudiar aquellos casos en los cuales estos órganos jurisdiccionales han sido llamados a aplicar tratados internacionales. ${ }^{1} \mathrm{Se}$ trata, en cambio, de reflexionar sobre aquellos casos en los que, prima facie, el derecho internacional no ha formado parte de la litis planteada a estos órganos, pero donde, finalmente, ha servido de apoyo para reforzar sus argumentos y resoluciones.

Así, lo que se busca es establecer el alcance y amplitud del derecho internacional en México, ya sea como parte del sistema jurídico (de conformidad con lo establecido en el artículo 133 constitucional) o como herramienta hermenéutica.

Antes de estudiar la postura que ha adoptado el Poder Judicial de la Federación, como primer paso, se expondrán los diversos esquemas teóricos que se han desarrollado para explicar la relación del derecho internacional con los sistemas jurídicos nacionales. Posteriormente, y por lo que corresponde a la SCJN, ${ }^{2}$ se analizará el amparo en revisión 120/2002 en el que se estableció la jerarquía normativa de los tratados internacionales; la controversia constitucional 5/2001, en la que se estudió la naturaleza jurídica de los husos horarios; el amparo directo en revisión $813 / 2003$, por el cual se utilizó la Declaración Universal de los Derechos Humanos como parte del sistema de normas nacional, y el amparo directo en revisión 2922/98, en virtud del cual se estableció la posibilidad de completar tipos penales con tratados internacionales.

Por lo que respecta a los TCC, hay tres criterios que resultan de gran relevancia. El amparo en revisión 799/2003, en el cual se señaló que la

1 Por ejemplo el amparo en revisión 1162/96, Segunda Sala, 10 de noviembre de 2000.

2 Para efectos del presente artículo no se hará distinción alguna entre precedentes derivados del tribunal pleno o de las salas. 
interpretación constitucional y legal debe obedecer a los principios pro homine y de maximización de los derechos humanos; ${ }^{3}$ así como, el amparo en revisión 173/2002, en virtud del cual se utilizó el derecho de igualdad para declarar inconstitucional el tipo penal de vagancia y malvivencia en Aguascalientes. Por último la aplicación de la Convención de Viena sobre Relaciones Consulares (Convención de Viena) que prevé el derecho de asistencia consular.

En cuanto a la metodología empleada es necesario hacer algunos comentarios para aclarar el alcance del corpus estudiado. Se debe señalar que resulta limitado extraer los argumentos de las tesis y jurisprudencias que se emitieron como resultado de estos precedentes, ${ }^{4}$ dado que en las mismas solamente se plasma la conclusión del razonamiento emitido. Como se mencionó, lo que se busca es averiguar cuál fue el razonamiento que dio como resultado dicho criterio. Entonces, es necesario recurrir a las ejecutorias y analizar los considerandos donde se expresaron los razonamientos relevantes y que auténticamente dieron sustento al resultado de la sentencia. ${ }^{5}$

Así, en este artículo se estudiarán únicamente los razonamientos relevantes para el derecho internacional. Es importante señalar que las ejecutorias deben resolver íntegramente los agravios que se presentan, muchos de los cuales no tienen relación alguna con la aplicabilidad del derecho internacional, por lo tanto, aunque parezca somero, en este estudio solamente se presenta la parte en la que se razonó sobre la pertinencia y aplicabilidad del derecho internacional. En consecuencia, escapa del alcance de este estudio hacer un análisis completo de la totalidad de las sentencias seleccionadas.

\section{BREVES CONSIDERACIONES TEÓRICAS}

En este apartado se tratará de explicar la relación entre derecho internacional y derecho interno. No es el objetivo de este trabajo hacer una

3 Véase amparo directo 202/2004, Cuarto Tribunal Colegiado en Materia Administrativa del Primer Circuito, 20 de octubre de 2004.

4 Me refiero a los párrafos que se publican en el Semanario Judicial de la Federación y su Gaceta o, más recientemente, en los sistemas IUS.

5 En ocasiones fue necesario recurrir a la unidad de enlace del Consejo de la Judicatura para conseguir el texto íntegro de las ejecutorias. 
exploración minuciosa de este tema, sino que se pretende exponer de forma breve cómo la doctrina ha abordado el tema de la relación entre normas jurídicas nacionales e internacionales, así como los problemas y soluciones que se han identificado.

Tradicionalmente, la relación entre el derecho internacional y el derecho interno de los Estados se ha explicado a través de las teorías monista y dualista. En virtud de la primera, las normas nacionales e internacionales se entienden como pertenecientes a un mismo sistema jurídico; mientras que la segunda prevé una clara división, conformando cada una un sistema jurídico por separado; sin embargo, las corrientes más modernas rechazan esta distinción tajante a favor de posturas más moderadas. ${ }^{6}$ Así, se identifica una tendencia en virtud de la cual los Estados tratan de cumplir con las normas de derecho internacional, a través de su uso como una herramienta de interpretación del derecho interno, incluyendo a las Constituciones, en lo que se ha denominado "internacionalización de las Constituciones nacionales". ${ }^{7}$

En realidad, estas teorías solamente adquieren importancia cuando hay un conflicto entre una norma de derecho internacional y una de derecho interno. Al respecto, Brownlie opina que no puede haber un conflicto real entre el derecho interno y el derecho internacional, ya que cada uno constituye un sistema que opera en ámbitos diversos; sin embargo, sí puede haber un conflicto con obligaciones internacionales o una inhabilidad de los Estados para actuar de forma consistente con el derecho internacional. Esto puede acarrear responsabilidad internacional en contra del Estado, pero no llega al extremo de invalidar el derecho interno. ${ }^{8}$ En otras palabras, el incumplimiento de las normas de cada sistema conlleva a consecuencias jurídicas diversas.

6 Véase Sepúlveda, César, Derecho internacional, México, Porrúa, 2004, p. 81. Según este autor, predomina un monismo moderado. Cfr. Herdegen, Matthias, Derecho internacional público, trad. de Marcela Anzola, México, UNAM-Fundación Konrad Adenauer, 2005, p. 167. En la práctica ha prevalecido el dualismo moderado, según el cual ambos sistemas tienen vida propia, pero limitados entre sí por la realidad jurídica de los Estados.

7 Véase Herdegen, op. cit., nota anterior, pp. 169 y 181. Véase, también, Virally, Michel, "Fuentes del derecho internacional", en Sorensen, Max (ed.), Manual de derecho internacional público, México, Fondo de Cultura Económica, 1994, p. 194.

8 Véase Brownlie, lan, Principles of Public International Law, 6a. ed., Oxford, Oxford University Press, 2003, pp. 33 y 34. 
Es importante aclarar que estas teorías se refieren al derecho internacional en general, es decir, a la incorporación (o no) de las fuentes de derecho reconocidas en este ámbito, entendidas como el derecho consuetudinario internacional y los tratados internacionales. ${ }^{9}$ En la Constitución Política de los Estados Unidos Mexicanos (Constitución federal) las referencias al derecho internacional se limitan a los tratados internacionales, los cuales forman parte del sistema jurídico nacional; ${ }^{10}$ sin embargo, no queda del todo claro cuál es el papel de la costumbre internacional, la cual se ha incorporado a los sistemas anglosajones a través del common law, o a través de disposiciones constitucionales en los sistemas europeos. ${ }^{11}$

Un ejemplo de lo anterior es la Constitución alemana, que en su artículo 25 señala: "Las normas generales del derecho de gentes (Volkerrecht) constituyen parte integrante del derecho federal, tendrán primacía sobre las leyes y crearán derechos y deberes de modo inmediato para los habitantes del territorio federal".

Por otro lado, es importante hacer una distinción en relación con los tratados. La doctrina ha identificado aquellos que son autoejecutables (self-executing) y los no autoejecutables. Al respecto, Sepúlveda indica que los primeros son aquellos que no dependen de una ley para su cumplimiento y, en todo caso, le corresponderá al Ejecutivo (instancia que celebró el tratado) su adecuación a través de disposiciones administrativas. Por su parte, los segundos se refieren a aquellos tratados que necesitan de una ley o, por lo menos, un reglamento para que puedan operar y llevarse a la práctica. ${ }^{12}$

Los problemas ocasionados por un posible conflicto entre derecho internacional y derecho interno surgen con los tratados no autoejecutables, pues mientras no se cree la ley de incorporación, puede existir una discrepancia entre el derecho interno y el tratado internacional. ${ }^{13}$

9 De las fuentes de derecho internacional se excluyen los principios generales de derecho, dado que éstos no provienen del derecho internacional, sino que provienen de los mismos sistemas jurídicos internos. Así, su incorporación no está vinculada al derecho comparado, lo cual excede los alcances de este estudio.

10 Véase Constitución federal, artículo 133.

11 Véase Virally, Michel, op. cit., nota 7, p. 194.

12 Véase Sepúlveda, César, op. cit., nota 6, p. 75.

13 Idem. El problema se ha exagerado por la doctrina, pues es mucho mayor la cantidad de tratados que se cumplen en relación a los que no se cumplen. Asimismo, cuando 
En definitiva, los tribunales tienen un papel fundamental en la armonización del derecho internacional con el derecho interno, pues, para evitar discrepancias y conflictos, es importante que se sigan las recomendaciones de la doctrina en el sentido de interpretar el derecho interno de conformidad con el derecho internacional $\mathrm{y}$, en última instancia, es a la judicatura a quien le corresponde la interpretación de las leyes, tratados y Constitución. Con estos antecedentes, se analizará cómo ha reaccionado el Poder Judicial de la Federación frente a esta tarea.

\section{SuPREMA CORTE DE JUSTICIA DE LA NACIÓN}

\section{Jerarquía normativa de los tratados internacionales}

El tema de la jerarquía normativa de los tratados internacionales no es cosa nueva en el sistema jurídico mexicano. El problema se origina en el texto del artículo 133 constitucional, que en la parte relevante señala: "Esta Constitución, las leyes del Congreso de la Unión que emanen de ella y todos los Tratados que estén de acuerdo con la misma, celebrados y que se celebren por el presidente de la República, con aprobación del Senado, serán la Ley Suprema de toda la Unión".

En ningún momento se ha cuestionado que la Constitución se encuentra en la cúspide de las relaciones normativas; por lo que la confusión surge del hecho de que no queda claro si hay una relación de jerarquía entre los tratados internacionales y las leyes federales y generales, emitidas por el Congreso de la Unión. ${ }^{14}$ Lo único que no se discute es que la Constitución federal se encuentra en la cúspide del sistema normativo mexicano.

La SCJN aportó una primera solución con base en el amparo en revisión 1475/98 en el cual se determinó que los tratados internacionales se encontraban jerárquicamente por encima de las leyes federales y generales; sin embargo, se trata de una tesis aislada que tardó cinco años en ser ratificada y, cuando se confirmó, se hizo con base en argumentos diversos a los que dieron origen a este criterio.

se implementa la ley que lo hace efectivo, cualquier conflicto se vuelve un conflicto entre leyes.

14 Véase Sepúlveda, Bernardo, Derecho internacional, México, Porrúa, 2006. Este autor sostiene que no existe una jerarquía normativa y ambos cuerpos normativos deben interpretarse conjuntamente y atendiendo a las reglas del conflictos de normas. 
En aquella ocasión el argumento central en el que se basó esta postura es que los tratados internacionales son "compromisos... asumidos por el Estado mexicano en su conjunto y comprometen a todas las autoridades frente a la comunidad internacional". ${ }^{15}$

A pesar de que dicho argumento es correcto, quedaron varias preguntas sin resolver, pues no se explicó cómo la superioridad normativa garantiza el cumplimiento con los tratados internacionales. Inclusive, no está del todo claro que con este argumento se prevea una diferencia normativa. Además, se obviaron cuestiones tan básicas como que el texto constitucional menciona primeramente a las leyes federales y generales, lo cual apuntaría a que éstas tienen superioridad normativa.

A pesar de estas objeciones, dudas y confusiones la SCJN reafirmó su criterio inicial en el amparo en revisión 120/2002. El tema central en este asunto era determinar si el Tratado de Libre Comercio de América del Norte prevalecía sobre leyes arancelarias.

Se trata de una resolución sumamente compleja pues se abordan diversos temas y se hacen afirmaciones en el dictum de gran trascendencia, si bien no para establecer la jerarquía normativa de los tratados internacionales sí para establecer las bases en la relación entre derecho interno y derecho internacional.

El primer aspecto que abordó la SCJN fue determinar el contenido de la frase "Ley Suprema de la Unión". Pero antes hace una diferencia entre leyes generales y leyes federales, señalando que estas últimas son aquellas que rigen solamente en el ámbito federal, de igual forma que las leyes estatales y del Distrito Federal solamente rigen en el ámbito de sus respectivas competencias. Si se supone que los jueces locales están obligados a aplicar leyes federales se estaría rompiendo con el esquema de distribución de competencias, lo cual no puede ser la finalidad del artículo 133. De esto se desprende que estas leyes emanadas del Congreso de la Unión, pero aplicables igualmente por cualquier autoridad, solamente pueden ser leyes generales, tal y como se señala en el párrafo que se transcribe:

15 Tratados inTERnACIONALES. SE UBiCAN JERÁRQUiCAMENTE POR ENCIMA DE LAS LEYES FEDERALES Y EN UN SEGUNDO PLANO RESPECTO DE LA CONSTITUCIÓN FEDERAL, Tribunal Pleno, Semanario Judicial de la Federación y su Gaceta, Novena Época, noviembre de 1999, p. 46. 
En ese tenor, podemos afirmar que las leyes del Congreso de la Unión a las que se refiere el artículo 133 constitucional, no corresponden a las leyes federales, considerando como tales aquellas que se limitan a regular las atribuciones que en la Constitución se confieren a determinados órganos con el objeto de trascender únicamente al ámbito federal, sino que se trata de las leyes generales, esto es, aquellas que válidamente pueden incidir en los todos los órdenes jurídicos parciales que integran al Estado mexicano. ${ }^{16}$

De esta forma la "supremacía constitucional" queda compuesta por la propia Constitución federal, los tratados internacionales y las leyes generales. Estos tres ordenamientos tienen supremacía jerárquica con respecto a las leyes federales y locales. Esta afirmación se aproxima mucho a la creación de un bloque de constitucionalidad en países como Colombia, donde jurisprudencialmente se ha reconocido que la Constitución comparte un mismo nivel jerárquico con los tratados internacionales. ${ }^{17}$ Para el caso mexicano, esta afirmación encuentra sustento en el siguiente párrafo:

En las condiciones relatadas, es posible concluir que, en términos del artículo 133 constitucional, los tratados internacionales, al ser parte de la Ley Suprema de toda la Unión, se ubican jerárquicamente por encima de las leyes federales y, por otra parte, atendiendo a las consideraciones de derecho internacional que serán desarrolladas a continuación, también por encima de las leyes generales; en el entendido de que esta Suprema Corte no se ha pronunciado respecto a la jerarquía de aquellos tratados internacionales cuyo contenido esté referido a derechos humanos, caso en el cual, pudiera aceptarse que la jerarquía de éstos corresponda a la de la Constitución federal misma, al concebirse dichos instrumentos internacionales como una extensión de lo previsto por ésta. ${ }^{18}$

En los siguientes párrafos, la SCJN trata de enfatizar el carácter internacionalista de la Constitución federal, señalando que en ella existen

16 Amparo en revisión 120/2002, Pleno, 13 de febrero de 2007, considerando segundo.

17 Véase Corte Suprema de Colombia, Sentencia C-225/95, 18 de mayo de 1995. Con esta resolución este alto tribunal consideró que las normas derivadas del derecho internacional humanitario tenían rango constitucional.

18 Amparo en revisión 120/2002, Pleno, 13 de febrero de 2007, Considerando Segundo. 
otros preceptos en los que se intenta armonizar el derecho internacional con el interno, como son la solidaridad internacional (artículo 3o.), los límites de los tratados de extradición (artículo 15) y la extensión de los mares nacionales y del espacio aéreo (artículo 42). Asimismo, se dice que en un mundo globalizado es indispensable que las Constituciones nacionales encuentren no solamente consistencia interna sino con la comunidad internacional. El último argumento señalado se basa en un recuento de diversas disposiciones en diversos Estados con el fin de ilustrar que existe una tendencia mundial por darle a los tratados internacionales una jerarquía superior a las leyes y, en ocasiones, también a la Constitución.

Hay un último argumento que es de relevancia para apoyar la idea de que los tratados internacionales deben de ser jerárquicamente superiores a las leyes generales. La SCJN indica, con base en la Convención de Viena sobre el Derecho de los Tratados, que en derecho internacional se reconoce la supremacía de éste sobre el derecho interno. En este tratado internacional se prevé que no puede haber disposiciones de derecho interno que justifiquen el incumplimiento con un tratado. Además se prevé como pieza fundamental del derecho de los tratados la cláusula pacta sunt servanda. Como consecuencia, otorgarle jerarquía normativa superior o igual a las leyes internas supondría romper con estos dos principios, que son compromisos internacionales adquiridos por México y congruentes con la idea de armonizar el derecho interno con el internacional. Es por ello que se refuerza la idea, ahora con argumentos propios del derecho internacional, de que los tratados internacionales deben sostener su superioridad con relación a las leyes federales y generales.

Así pues, con todos los anteriores argumentos centrales y de apoyo, la SCJN estableció una nueva jerarquía normativa, pues en ella se distinguen las leyes generales de las federales, lo cual no se hizo en el primer criterio, y se colocan por encima de ambas a los tratados internacionales. Incluso hay indicios para pensar que se han tomado pasos importantes para establecer un bloque de constitucionalidad.

A pesar del avance que significó esta decisión, aún quedó pendiente determinar cuál es el papel que juegan las demás normas de derecho internacional en el sistema jurídico mexicano. A pesar de ello, por lo menos en cuanto a la costumbre internacional, ya hubo un pronunciamiento importante (incluso previo al que se analizó aquí), como a continuación se verá. 


\section{Incorporación de la costumbre internacional}

En la controversia constitucional relativa a la utilización de los husos horarios en México, se discutieron varios aspectos de la relación de facultades que, de conformidad con la Constitución federal, tienen el Congreso de la Unión y el presidente de la República. En este contexto, la SCJN se vio en la necesidad de establecer si los husos horarios son una medida, pues en este caso, el Legislativo podría emitir leyes para su regulación, ${ }^{19}$ lo cual hubiera dado por concluido el conflicto.

Para sustentar la naturaleza de los meridianos y su relación con los husos horarios, la SCJN decidió explicar que los meridianos y su conteo a partir de Greenwich son normas jurídicas que se adoptaron en la Conferencia Internacional sobre Meridianos celebrada en Washington D. C., en 1884, pero que estas pláticas no culminaron en un tratado internacional:

Sin embargo, los acuerdos tomados en dicha Conferencia se han venido respetando conforme a la costumbre internacional, pues desde la vigencia de la Constitución de mil novecientos diecisiete, se encuentra que para el establecimiento de husos horarios en la República mexicana se ha considerado el Meridiano de Greenwich, que como se ha dicho fue adoptado como meridiano cero u origen. Así se advierte de diversos decretos emitidos por el presidente de la República, sobre ese asunto. ${ }^{20}$

A continuación, el tribunal pleno transcribió una serie de decretos presidenciales, que para establecer los horarios en el país toman como referencia el meridiano de Greenwich. Es importante destacar que ninguno de los acuerdos y decretos presidenciales establecía los meridianos, sino que en ellos se reconoce la norma de costumbre internacional como referente; tal y como se desprende de la siguiente afirmación: “... los decretos que sobre husos horarios se han emitido en el país, han tomado como referencia para ello el Meridiano de Greenwich, que se insiste, fue el adoptado como de origen para establecer tales husos horarios en la Conferencia a que se ha hecho mérito". ${ }^{21}$

19 Véase Constitución federal, artículo 73, fracción XVIII.

20 Controversia constitucional 5/2001, Tribunal Pleno, 4 de septiembre 2001, p. 146.

21 Controversia constitucional 5/2001, considerando séptimo, p. 183 (enfásis del autor). 
De lo anterior, se desprende que la SCJN establece la posibilidad de que la costumbre internacional forme parte del sistema jurídico nacional, toda vez que acepta que los acuerdos y decretos presidenciales regulen cierta materia (en este caso el reconocimiento internacional de los meridianos y los husos horarios a partir de Greenwich) con base en una norma considerada como derecho positivo mexicano, pero cuyo sustento original se encuentra en el derecho consuetudinario internacional. Lo relevante de esta afirmación es que el artículo 133 constitucional establece que los tratados internacionales son parte de lo que constituye la "Ley Suprema de toda la Unión", pero no reconoce expresamente alguna otra fuente de derecho internacional. ${ }^{22}$

Lo que se deduce de esta tesis es que también pueden formar parte del sistema de normas en México, aquellas derivadas de la costumbre internacional. Como mínimo, la SCJN ha establecido que es válido fundar un acto de autoridad en la costumbre internacional y, en su caso, solamente sería necesaria su regulación..$^{23}$ Pero aun en este último supuesto, más conservador, la interpretación establecida en la controversia constitucional 5/2001 va más allá de lo que se puede desprender de la simple lectura del texto constitucional.

En este sentido, los decretos presidenciales que habían regulado los husos horarios y los meridianos no habían hecho otra cosa que reglamentar una disposición de costumbre internacional, de igual forma que se haría si dicha norma jurídica proviniera de un tratado no autoejecutable.

\section{Incorporación de resoluciones de la Asamblea General}

En el amparo directo en revisión 813/2003, al establecer el alcance del derecho a la estabilidad laboral y su protección constitucional, la SCJN incorporó dentro de sus argumentos la posibilidad de acudir a la Declaración Universal de Derechos Humanos como algo más que una herra-

22 El artículo 38 del Estatuto de la Corte Internacional de Justicia establece lo que tradicionalmente se ha reconocido como las fuentes de derecho internacional, las cuales son: los tratados internacionales, la costumbre internacional y los principios generales de derecho reconocidos por los principales sistemas jurídicos del mundo y de forma auxiliar, la jurisprudencia y la doctrina.

23 Este parece ser el sentido de la tesis aislada que surgió de este precedente, según se desprende de su rubro: HUSOS HORARIOS. LOS ACUERDOS DE LOS QUE EMANAN HAN SIDO RESPETADOS POR MÉXICO CONFORME A LA COSTUMBRE INTERNACIONAL. 
mienta de interpretación. Al respecto, es importante mencionar que la declaración no es un tratado internacional, sino que su base jurídica es una resolución de la Asamblea General de las Naciones Unidas. En efecto, de la argumentación de la SCJN se desprende que este tipo de determinaciones también forman parte de nuestro sistema jurídico, aunque no se mencionen textualmente en el artículo 133 constitucional. En la parte relevante del fallo se señaló lo siguiente:

A mayor abundamiento, es cierto que el artículo 23, punto 1, de la Declaración Universal de los Derechos Humanos aprobada y promulgada por la Asamblea General de las Naciones Unidas reconoce el derecho que tiene toda persona contra el desempleo; sin embargo, ello no impide que en la Constitución Federal y la Ley Federal de los Trabajadores al Servicio del Estado reglamentaria del artículo 123, apartado "B", se establezcan modalidades en torno a los trabajadores de confianza, tales como su falta de estabilidad en el empleo, dado que esa modalidad no propicia el desempleo sino que sólo tiende a salvaguardar la prestación del servicio público en óptimas condiciones, que pueden verse afectadas si el Estado tuviera el imperativo de reinstalar a servidores públicos catalogados de confianza en perjuicio de la buena marcha de la actividad estatal. ${ }^{24}$

Aunque este párrafo se redactó en términos tales que hace suponer que la declaración fue usada meramente como un apoyo argumentativo y no como parte central de la determinación del tribunal pleno, lo cierto es que en ningún momento se negó la aplicabilidad de la declaración, sino que simplemente se aclaró que su contenido no es obstáculo para establecer modalidades que afecten la estabilidad laboral del trabajador de confianza, en función del buen desempeño del servicio público. En todo caso, se trata de una interpretación sistemática entre la declaración, la constitución federal y la Ley Federal de los Trabajadores al Servicio del Estado. Asimismo, plantea un equilibrio de intereses en el cual se consideró prioritario el servicio público, lo cual corrobora lo anterior, pues para establecer este equilibrio fue necesario reconocer el derecho consagrado en la declaración.

Por lo tanto, aunque no se pueda afirmar con exactitud cuál es el lugar y jerarquía que ocupa la declaración y, en general, las resoluciones de la asamblea, es innegable que forman parte del sistema jurídico mexi- 
cano. ${ }^{25}$ De esta forma, la SCJN dio un paso importante en la incorporación de fuentes de derecho internacional al sistema jurídico mexicano, pues se establece la posibilidad de que las resoluciones de la Asamblea, cuya obligatoriedad está en duda en el mismo derecho internacional, ${ }^{26}$ formen parte de nuestro sistema jurídico. ${ }^{27}$

\section{Integración de tipos penales}

En el amparo directo en revisión 2922/98 se estableció otro precedente importante para la incorporación del derecho internacional en México, ya que se sostuvo la constitucionalidad de aquellos tipos penales que remiten a los tratados internacionales para completar la descripción de la conducta penalizada. Se trata de los tipos penales en blanco, los cuales se pueden definir como "aquellos en los que la conducta no aparece plenamente descrita en cuanto que el legislador se remite al mismo o a otro ordenamiento jurídico para actualizarla o concretarla....". ${ }^{28}$

En esencia, la impugnación se basó en el hecho de que la efedrina no era una sustancia prohibida por el Código Penal Federal ni por la Ley General de Salud, al momento en el que el recurrente fue detenido en posesión de la misma. Según la impugnación, el Convenio de las Naciones Unidas contra el Tráfico de Estupefacientes y Substancias Psicotrópicas, que contempla la efedrina como sustancia prohibida, no forma parte del derecho positivo mexicano $\mathrm{y}$, por ende, no podría considerársele como una sustancia prohibida adicional a las contempladas en la legislación,

25 En este sentido está redactada la tesis que surgió de esta resolución, cuyo rubro es el siguiente: Trabajadores de CONFIANZA AL SERVicio DEL Estado. Su falta de ESTABILIDAD EN EL EMPLEO, DERIVADA DEL ARTíCUlO 123, APARTADO B, FRACCIÓN XIV, DE LA CONSTITUCIÓN FEDERAL, NO VIOLA EL DERECHO A SER PROTEGIDO CONTRA EL DESEMPleo eStablecido en la Declaración UniVERSAL de los Derechos Humanos.

26 Véase Toro Huerta, Mauricio Iván del, "El fenómeno del soft law y las nuevas perspectivas en derecho internacional", Anuario Mexicano de Derecho Internacional, México, UNAM, vol. 6, 2006. En donde se plantea la obligatoriedad de las normas de soft law, incluyendo las resoluciones de la Naciones Unidas y su efecto persuasivo, no propiamente vinculante y obligatorio.

27 Podría argumentarse que la SCJN reconoció que las resoluciones de la Asamblea General son el reflejo del consenso internacional, sin embargo de la ejecutoria no se desprende dicho razonamiento. Sobre este tema véase D'Amato, Anthony, "On Consensus", Canadian Yearbook of International Law, 1970, vol. 8, p. 141.

28 Véase Reyes Echandía, Alfonso, Diccionario de Derecho Penal, 6a. ed., Bogotá, Temis, 2004, p. 44. 
para efectos de los delitos de narcotráfico. En todo caso, los contenidos de dicho tratado internacional deben incorporase en la legislación, lo cual de hecho ocurrió en una fecha posterior. Sin embargo, la SCJN, en Pleno, determinó que:

Del propio contenido del dispositivo constitucional en análisis, se observa que de manera clara el Constituyente otorga el rango de ley del país a los tratados celebrados y que se celebren por el presidente de la República, sin más condición para ello que la de que no sean contrarios a la propia Constitución y sean aprobados por el Senado, sin que para ello sea necesario posterior acto legislativo. Así, satisfechos los apuntados requisitos, lo pactado en los tratados queda automáticamente incorporado a nuestro derecho interno, por así haberlo dispuesto el Constituyente..$^{29}$

Más allá de la interpretación textual del artículo 133 constitucional que fue la base de esta afirmación, la SCJN consideró que los tratados internacionales son ordenamientos jurídicos propicios para completar tipos penales, siempre y cuando el Legislativo prevea dicha remisión, tal y como ocurrió en el caso particular del artículo 193 del Código Penal Federal.

Esta aclaración parece importante, pues la SCJN no atendió el supuesto en el cual el tipo penal, por completo, se encuentra contemplado en un tratado internacional, ni el supuesto en el cual la remisión no esté expresamente contemplada en la legislación. Estas hipótesis normativas escapan del alcance de esta determinación y posiblemente sean declaradas inconstitucionales, si se toma en consideración que en esta resolución se recalcó el hecho de que el tratado internacional impugnado no establecía tipo penal alguno, sino que es solamente un compromiso entre los Estados parte para combatir el tráfico de estupefacientes y psicotrópicos. ${ }^{30}$

Sin embargo, una interpretación en este sentido dejaría sin efectos el artículo 6o. del Código Penal Federal y 50 de la Ley Orgánica del Poder Judicial de la Federación, los cuales contemplan la posibilidad de que los jueces de distrito conozcan de delitos establecidos en tratados internacionales. Por el contrario, si estas remisiones del Congreso son válidas, en-

29 Amparo directo en revisión 2922/98, tribunal pleno, 18 de mayo de 1999, pp. 149 y 150.

30 Ibidem, p. 161. 
tonces pudiera pensarse que estas disposiciones expresan el reconocimiento del Congreso (aunque planteado en forma genérica) de los tipos penales que se encuentren exclusivamente en tratados internacionales.

En conclusión, de esta resolución se deriva la posibilidad de que los tipos penales que se encuentran en diversos tratados internacionales sean considerados autoejecutables, lo cual haría, en principio, innecesario legislar sobre estos temas. Si bien existen varios delitos internacionales o transfronterizos incluidos en la legislación actual, tales como la tortura, ${ }^{31}$ el genocidio ${ }^{32}$ y la desaparición forzada de personas, ${ }^{33}$ hay muchos otros que aún no se han incorporado, ${ }^{34}$ por lo que esta interpretación podría ser una forma de homologar el derecho internacional con el derecho penal interno.

\section{TRIBUNALES COLEGIADOS DE CIRCUITO}

\section{Reconocimiento obligatorio del principio pro homine y del principio} de maximización de los derechos humanos o estándar mínimo

En el amparo en revisión, 799/2003, el Cuarto Tribunal Colegiado en Materia Administrativa del Primer Circuito, resolvió un caso en el cual la parte quejosa había sido obligada a retirarse de las fuerzas armadas porque los resultados de la prueba Elisa indicaban que era VIH positivo. En la parte relevante, este TCC tuvo que interpretar los artículos 22 y 197 de la Ley del Instituto de Seguridad Social para las Fuerzas Armadas Mexicanas, que regulan el retiro por inutilidad en actos fuera del servicio.

El TCC determinó que estos preceptos debían ser interpretados a la luz del derecho a la salud, a la estabilidad laboral y a la no discriminación, contemplados en la Constitución federal, leyes federales y en diversos tratados internacionales. ${ }^{35}$ Así, el órgano jurisdiccional hizo una revisión de las normas contempladas en estas tres clases de ordenamientos jurídicos, con el fin de determinar hasta qué grado la actuación e inter-

31 Véase Ley Federal para Prevenir y Sancionar la Tortura, artículo 30.

32 Véase Código Penal Federal, artículo 149-bis.

33 Véase Código Penal Federal, artículos 215-A, y ss.

34 Véase Convenios de Ginebra de 1949.

35 Véase amparo en revisión 799/2003, Cuarto Tribunal Colegiado en Materia Administrativa del Primer Circuito, 21 de abril de 2004, pp. 88 y 89. 
pretación legal de las autoridades militares había vulnerado las garantías de los quejosos. ${ }^{36}$

En el espacio dedicado a los tratados internacionales, se comenzó por recalcar la aplicabilidad de los $\operatorname{mismos}^{37}$ y el reconocimiento que hacen del principio pro homine, principalmente, en el Pacto Internacional de Derechos Civiles y Políticos ${ }^{38}$ y en la Convención Americana de Derechos Humanos. ${ }^{39}$

Consecuentemente, el acto de aplicación se había emitido sin tomar en cuenta los tratados internacionales y, en especial, el principio pro homine. El párrafo relevante señala lo siguiente:

Por lo que al haber decretado las responsables el retiro del quejoso sin ser escuchado y tomando solamente en cuenta la inutilidad derivada de ser portador de VIH, se traduce en un trato discriminatorio, el cual está prohibido por nuestra Constitución y en los diversos ordenamientos citados, por lo tanto el acto de aplicación de los ordenamientos reclamados es inconstitucional, y procede conceder el amparo solicitado, atendiendo también al principio pro homine (el cual está incorporado en los tratados), cuya definición de Martín Abregó y Cristian Courtis (en La aplicación de los tratados internacionales sobre derechos humanos por los tribunales locales, Editorial del Puerto, página 163) a continuación se cita: "El principio pro homine es un criterio hermenéutico que informa todo el derecho de los derechos humanos, en virtud del cual se debe acudir a la norma más amplia, o a la interpretación más extensiva, cuando se trata de reconocer derechos protegidos e, inversamente, a la norma o a la interpretación más restringida cuando se trata de establecer restricciones permanentes al ejercicio de los derechos de suspensión extraordinaria. El principio coincide con el rasgo fundamental de derecho de los derechos humanos, esto es, estar siempre a favor del hombre". ${ }^{40}$

36 Ibidem, pp. 89 y ss.

37 Ibidem, p. 96

38 Ibidem, p. 102. "También se prohíbe la restricción o menoscabo de alguno de los derechos fundamentales reconocidos o vigentes en un país a pretexto de que éste pacto no los reconoce o los reconoce en menor grado (artículo 5.2.2 principio pro homine)".

39 Ibidem, pp. 102 y 103. "Este tratado prohíbe expresamente la supresión del goce y ejercicio de los derechos $v$ libertades reconocidos por esta convención o de cualquier derecho o libertad reconocido de acuerdo con las leyes de los estados partes (artículo 29 principio pro homine)".

40 Ibidem, pp. 105 y 106. 
En esencia, la postura de este TCC es que el amparo se pudo haber concedido porque el acto de autoridad era contrario a la Constitución federal, además de ser ilegal y violatorio de tratados internacionales; sin embargo, también por el hecho de que se debieron haber interpretado los artículos impugnados en consonancia con el resto del sistema jurídico (interpretación sistemática) y de conformidad con la salvaguarda y aplicación amplia de los derechos humanos, que no es otra cosa que el principio pro homine (tal y como se enfatiza con las definiciones transcritas en la ejecutoria).

Así, se puede llegar a la conclusión de que el principio pro homine, el cual ha sido reconocido en tratados en materia de derechos humanos, debe aplicarse no sólo en la interpretación constitucional y legal, sino también en la emisión de todos los actos de autoridad. ${ }^{41}$

Cabe señalar, que de este precedente se desprendió también la siguiente tesis aislada:

TRATADOS INTERNACIONALES. SU APLICACIÓN CUANDO AMPLÍAN Y REGLAMENTAN DERECHOS FUNDAMENTALES. Conforme al artículo 133 constitucional, la propia Constitución, las leyes del Congreso de la Unión que emanen de ella y todos los tratados que estén de acuerdo con la misma, celebrados y que se celebren por el presidente de la República, con aprobación del Senado, serán la ley suprema de toda la Unión. Ahora bien, cuando los tratados internacionales reglamentan y amplían los derechos fundamentales tutelados por la carta magna, deben aplicarse sobre las leyes federales que no lo hacen, máxime cuando otras leyes también federales, los complementan. ${ }^{42}$

41 Véase PrinciPIO PRO HOMINE. Su APLICACIÓN ES OBLIGATORIA. Semanario Judicial de la Federación y su Gaceta XXI, Novena Época, Tribunales Colegiados de Circuito, febrero de 2005, p. 1744. Este mismo TCC enfatizó en otra oportunidad la obligatoriedad de este canon de interpretación, derivado de su inclusión en el Pacto Internacional de Derechos Civiles y Políticos y la Convención Americana de Derechos Humanos, ambos de observación obligatoria, de conformidad con el artículo 133 constitucional. Véase también recurso de apelación 1/2004-PS (Juan N. Silva Meza). En este voto particular se ha propuesto que la Constitución federal sea interpretada de conformidad con "la dinámica de la comunidad internacional". Dentro de esta afirmación estaría incluido no sólo el principio pro homine, sino cualquier disposición de derecho internacional aplicable a un caso concreto.

42 Semanario Judicial de la Federación y su Gaceta, XX, Tribunales Colegiados de Circuito, Novena Época, septiembre de 2004, p. 1896. 
Si bien en la ejecutoria no se abunda en torno a cómo se llega al reconocimiento o aplicación de este principio hermenéutico, ${ }^{43}$ es importante señalar que éste se refiere al principio de maximización de derechos y estándar mínimo. Cabe notar que si bien estos dos criterios de interpretación están relacionados en la medida que tienen por objeto el lograr el respeto más amplio a los derechos humanos, se trata de técnicas de hermenéutica distintas.

\section{El derecho internacional de los derechos humanos como herramienta hermenéutica}

En la línea del supuesto anterior se puede identificar un caso en el cual los instrumentos de derechos humanos son utilizados para interpretar la Constitución federal. En el amparo en revisión 173/2002, radicado en el Tercer Tribunal Colegiado del Vigésimo Tercer Circuito, se declaró inconstitucional el artículo 190 del Código Penal de Aguascalientes ${ }^{44}$ que tipificaba la vagancia y malvivencia. ${ }^{45}$

En un primer momento, el TCC analizó el artículo 10 de la Constitución federal, que contiene (entre otros preceptos) la garantía de libertad personal. Antes de establecer que este tipo penal violaba dicha garantía, se procedió a definir el concepto de "libertad personal", para lo cual se recurrió a la doctrina y a la Declaración de los Derechos del Hombre y del Ciudadano, a saber:

43 Véase amparo en revisión 799/2003, p. 103. Aparece una breve mención sobre la reglamentación de la Constitución federal a través de los tratados.

44 El artículo 190 del antiguo Código Penal de Aguascalientes a la letra señalaba que: La vagancia y malvivencia consiste en no dedicarse el inculpado a un trabajo honesto, sin causa justificada, y tener malos antecedentes, comprobados por datos de los archivos judiciales o de las oficinas policíacas. Se estimarán como malos antecedentes, para los efectos de este artículo, ser identificado como peligroso contra la propiedad o explotador de prostitutas o traficante de narcóticos, toxicómano ebrio habitual, tahúr o mendigo simulador. Al responsable de vagancia y malvivencia se le aplicarán de 6 meses a 2 años de prisión y vigilancia de autoridad de 6 meses a 1 año.

45 Esta tesis eventualmente formó la jurisprudencia siguiente: VAGANCIA Y MALVIVENCIA. El artículo 190 del Código Penal del Estado de Aguascalientes, al establecer como elemento del cuerpo del delito que el inculpado no se dedique a un trabajo honesto sin causa justificada, transgrede la garantía de igualdad jurídica contenida en el artículo 10 de la Constitución federal. Semanario Judicial de la Federación, Novena Época, Tribunales Colegiados de Circuito, XVI, octubre de 2002, p. 1272. 
Ello es así, porque la libertad estriba en la voluntad de la persona a hacer o no hacer algo, siempre que esa acción u omisión no perjudique a otros, pues concebida como un derecho fundamental, no es posible la restricción de la misma, en la medida en que el artículo 40 de la Declaración de los Derechos del Hombre y del Ciudadano establece: "La libertad consiste en hacer todo lo que no perturbe a los otros: en consecuencia el ejercicio de los derechos naturales de cada hombre sólo tiene los límites que aseguren a los otros miembros de la sociedad, el disfrute de los mismos derechos. Esos límites no pueden estar determinados en la ley". ${ }^{46}$

Este uso del derecho internacional es de especial interés pues ilustra de qué forma sirve para interpretar el texto constitucional. En este caso, el concepto "libertad personal" se encontraba contemplado en la Constitución federal, pero no se le otorgaba un significado. Así, este TCC optó por recurrir a los instrumentos de derechos humanos que se encuentran en el ámbito internacional para darle contenido a dicho concepto. Además de ser útil cuando en el derecho interno se encuentran términos ambiguos, hay certeza de que la interpretación de la Constitución federal será acorde con el derecho internacional y compatible con los derechos humanos.

Es importante resaltar que utilizar los derechos humanos es una tendencia global. En el caso de México, se desprende de una obligación derivada del artículo 29 de la Convención Americana, como se vio líneas arriba; sin embargo, en el artículo 21 (3) del Estatuto de Roma de la Corte Penal Internacional se establece una regla de interpretación similar, en virtud de la cual se obliga a la Corte Penal Internacional a interpretar las disposiciones del propio Estatuto de conformidad con los derechos humanos internacionalmente reconocidos. Dicho precepto literalmente señala:

La aplicación e interpretación del derecho de conformidad con el presente artículo deberá ser compatible con los derechos humanos internacionalmente reconocidos, sin distinción alguna basada en motivos como el género, definido en el párrafo 3 del artículo 7o., la edad, la raza, el color, la re-

46 Amparo en revisión 173/2002, Tercer Tribunal Colegiado del Vigésimo Tercer Circuito, 10 de julio de 2002, Considerando Sexto (en este caso, solamente se pudo extraer del sistema IUS la parte conducente de la sentencia por lo que no es posible precisar el número de página en el que se encuentran los argumentos). 
ligión o el credo, la opinión política o de otra índole, el origen nacional, étnico o social, la posición económica, el nacimiento u otra condición.

Consecuentemente, el tipo penal de vagancia y malvivencia, al establecer que el trabajo es una obligación y no un derecho, contraviene la garantía de libertad personal, tal y como se concluye en la sentencia:

Es decir, los preceptos en comento [5o. y 123 de la Constitución federal y 23 de la Declaración de Derechos del Hombre y del Ciudadano] no establecen ni obligación ni derecho alguno del gobernado a no trabajar, sino que la garantía que tutelan es que no se le puede obligar a que se dedique a un trabajo determinado sin su pleno consentimiento y sin retribución alguna; lo anterior deriva precisamente de la garantía de libertad personal que todo ciudadano tiene conforme al artículo 10 y demás de la Constitución federal. ${ }^{47}$

A pesar de ello, a continuación el TCC tuvo que responder al alegato de que la Declaración Americana de Derechos y Deberes del Hombre prevé la obligación de tener un trabajo. Al darle respuesta a este argumento, confirmó que el tipo penal violaba la libertad personal como derecho constitucional y no había una violación directa a la declaración universal, la cual había sido usada solamente para darle contenido a este concepto. El párrafo conducente señala lo siguiente:

No es obstáculo a lo anterior lo estatuido por el artículo XXXVII de la Declaración Americana de los Derechos y Deberes del Hombre, cuya ratificación se recibió en la Secretaría General de la Organización de Estados Americanos el veinticuatro de marzo de mil novecientos ochenta y uno, que establece el deber de toda persona de trabajar dentro de su capacidad y posibilidades, a fin de obtener los recursos para su subsistencia o en beneficio de la comunidad; en razón de que para determinar la constitucionalidad o no de un precepto, éste debe confrontarse con la Constitución federal y no con las obligaciones que un tratado establece, dado que éste no puede estar por encima de las garantías y prerrogativas que la propia Constitución otorga a las personas, puesto que los tratados internacionales se encuentran en un segundo plano por debajo de la ley fundamental de la nación. 
En líneas posteriores, el TCC señala que este tipo penal también viola la garantía de igualdad jurídica consagrada en el mismo artículo 10. constitucional, así como en el artículo 7o. de la Declaración Universal y 23 del Pacto Internacional de Derechos Civiles y Políticos; dado que para no incurrir en el delito, la persona debe de justificar el hecho de que no tenga trabajo. En tal virtud las personas adineradas siempre podrán justificar su falta de empleo al no requerirlo para subsistir, mientras que las personas que no cuentan con recursos nunca lo podrán justificar.

Sin embargo, para efectos del presente estudio, dicha afirmación no es del todo relevante, pues el TCC solamente afirmó que había una violación a dichos instrumentos internacionales, así como a la Constitución federal, por lo que en este rubro no se utilizaron estos acuerdos internacionales como herramientas de interpretación.

En conclusión, este caso ilustra cómo es posible recurrir al derecho internacional para buscar definiciones, contenidos, límites y alcances de conceptos y términos empleados en el derecho interno (incluyendo la Constitución federal); sin que ello se traduzca en una aplicación directa de los instrumentos internacionales.

\section{Interpretación de la Convención de Viena} sobre Relaciones Consulares

En el amparo directo 98/2007 el Primer Tribunal Colegiado en Materia Penal del Segundo Circuito se interpretó el derecho a la asistencia consular previsto en este tratado internacional y reafirmado en la Opinión Consultiva OC-16/99 de la Corte Interamericana de Derechos Humanos, la cual se cita en esta resolución judicial. Asimismo, señaló que este derecho también es aplicable en casos de extradición.

Lo primero que aportó el tribunal colegiado es aclarar el alcance y propósito que tiene el derecho a la asistencia consular. Se trata de un derecho que contiene dos vertientes, un derecho de los funcionarios consulares a asistir a sus connacionales y un derecho procesal del inculpado de contar con el apoyo de los propios funcionarios consulares. Dichas facetas se encuentran en los artículos 5o. y 36 de la Convención de Viena.

Con base en el primer derecho, las autoridades de procuración y administración de justicia tienen la obligación de comunicar a los consulados cuando tengan como detenido a uno de sus connacionales; de tal manera que los funcionarios estén en posibilidades de auxiliar al inculpado. 
El propósito de esta ayuda consular fue mencionado en la referida opinión consultiva. Este tribunal colegiado amplió los razonamientos al señalar:

Así, se patentiza la necesidad de un trato diferenciado para los desiguales, en el caso, el reconocimiento del derecho de un extranjero detenido y sometido a proceso penal, de que se le notifique su situación jurídica a las instituciones diplomáticas de su nacionalidad, a efecto de garantizarle, por sus circunstancias subjetivas, una adecuada defensa, al encontrarse bajo la jurisdicción de autoridades distintas a las de su país. ${ }^{48}$

Y agregó:

En efecto, para alcanzar sus objetivos, el proceso debe reconocer y resolver los factores de desigualdad real de quienes son llevados ante la justicia. Es así como se atiende el principio de igualdad ante la ley y los tribunales y a la correlativa prohibición de discriminación. La presencia de condiciones de desigualdad real obliga a adoptar medidas de compensación que contribuyan a reducir o eliminar los obstáculos y deficiencias que impidan o reduzcan la defensa eficaz de los propios intereses. Si no existieran esos medios de compensación, ampliamente reconocidos en diversas vertientes del procedimiento, difícilmente se podría decir que quienes se encuentran en condiciones de desventaja disfrutan de un verdadero acceso a la justicia y se benefician de un debido proceso legal en condiciones de igualdad con quienes no afrontan esas desventajas. ${ }^{49}$

El tribunal colegiado prosiguió a señalar que la asistencia consular forma parte de las formalidades esenciales del procedimiento a las que hace referencia el artículo 14 constitucional y deberá ser considerada como una de las violaciones al procedimiento a las que hace referencia el artículo 160, fracción II de la Ley de Amparo. Aunque dicho precepto se limita al derecho de nombrar un abogado defensor, el tribunal colegiado incluyó la asistencia consular por analogía. Como se desprende del siguiente párrafo:

48 Amparo directo 98/2007, Primer Tribunal Colegiado del Segundo Circuito, considerando quinto A.

49 Idem. 
En efecto, a criterio de este tribunal de control constitucional, por identidad jurídica, la falta de notificación de la detención y prisión preventiva del extranjero... a los funcionarios consulares respectivos, para posibilitar su comunicación y estrategia de defensa, es un caso análogo a la fracción II [del artículo 160 de la Ley de Amparo], pues, como se vio, era un imperativo legal del juez del proceso hacer saber la situación jurídica del entonces procesado a dichos representantes, en términos de la Convención antes referida.

Otro aspecto importante es que en el caso que dio pauta a la resolución el proceso penal inició en virtud de una extradición concedida por Estados Unidos, país de origen del inculpado; sin embargo, el tribunal colegiado aclaró que incluso en estos casos, en los cuales se puede deducir el conocimiento de la detención por parte de las autoridades consulares, es necesario notificarlas para hacer efectivo este derecho. Por lo importante del razonamiento resulta necesaria su trascripción:

Sin que sea óbice a lo antes dicho, la circunstancia que la detención judicial del aquí quejoso se debió a su extradición solicitada por México al país vecino del norte; pues ello no exime al órgano judicial de realizar tal notificación respecto de la detención judicial ni en relación con la prisión preventiva; dado que, como se ha dicho, tal carga procesal se exige por el numeral 36 de la Convención de Viena sobre Relaciones Consulares ante cada una de esas diversas situaciones jurídicas; pues lo que se pretende, en este último caso, es materializar la adecuada defensa del procesado extranjero, lo que se logra al notificar "sin demora" la detención del justiciable; máxime si se pondera, por un lado, que la Convención de Viena sobre Relaciones Consulares no contiene excepción alguna al respecto, por lo que donde la ley no distingue, el juez no debe hacerlo, pues ello implica la violación del principio de exacta aplicación de la ley; en segundo lugar, el auto de formal prisión no es una consecuencia forzosa e indefectible de la detención material, pues el juez puede, si así lo estima, decretar libertad por falta de elementos para procesar con las reservas de ley; por lo que no es válido aseverar apriorísticamente y sin fundamento alguno que por existir el antecedente de su extradición internacional, la representación diplomática de su país estaba legal y materialmente notificada de su situación jurídica; máxime si se pone en riesgo su derecho fundamental de la adecuada defensa y el previo y debido proceso legal, lo que debe satisfacerse plenamente; no obstante, se itera, de la totalidad de las constancias de la causa inexiste el auto que ordenara la comunicación a dicha representación diplomática ni constancia de que ésta se efectuó; tampoco cons- 
tancia de que al otroro procesado se le hicieron saber sus derechos de asistencia consular. ${ }^{50}$

Ciertamente el tribunal colegiado basó gran parte de su determinación, la cual concluyó con la reposición del procedimiento, en la Opinión Consultiva de la Corte Interamericana; sin embargo, lo novedoso de estos criterios es que se expusieron algunas cuestiones que no abordó a profundidad u omitió la instancia internacional en su determinación. La explicación del propósito que ofrece el tribunal nacional es más profunda, pues toma en consideración aspectos de igualdad y discriminación que no fueron tocados cabalmente por la corte. Igualmente, es novedoso establecer que el derecho internacional se encuentra vigente aun en los casos de extradición. En este supuesto no hay precedentes, por lo que sus razonamientos son de gran valía para el desarrollo del derecho a la asistencia consular en otras instancias.

Resulta curioso que el tribunal colegiado haya visto la necesidad de justificar con criterios judiciales extranjeros y nacionales el uso de la opinión consultiva como una herramienta hermenéutica; sin embargo, al señalar que en diversos tribunales sudamericanos es cotidiano acudir a los criterios de la Corte Interamericana en apoyo de sus criterios se consiguió otro objetivo importante para el presente estudio.

A diferencia del criterio analizado en el apartado anterior, en donde se empleó la Declaración Universal de Derechos Humanos para interpretar un código penal, este tribunal colegiado no se limita al uso de tratados internacionales o instrumentos de las Naciones Unidas como apoyos en la interpretación. En este caso, se empleó como herramienta de interpretación una resolución judicial internacional, lo cual abre una vertiente distinta, en el uso de instrumentos internacionales en la interpretación. Inclusive, su uso reiterado de criterios extranjeros hace suponer que no solamente las sentencias internacionales, sino también las extranjeras, pueden emplearse como herramientas hermenéuticas, tal y como se resume en el párrafo final del apartado bajo estudio:

La interpretación realizada por este Primer Tribunal Colegiado en Materia Penal del Segundo Circuito no implica, en modo alguno, integrar la norma, sino simplemente desentrañar su más puro sentido, a la luz de los tra- 
tados internacionales en materia de derechos fundamentales, que, como se vio, forman parte de nuestro derecho interno, por haber sido incorporados conforme a la ley. En tanto que, respecto de las sentencias pronunciadas por la Corte Suprema de Argentina y la Sala Constitucional de la Corte Suprema de Costa Rica, que se han invocado en esta ejecutoria, si bien no forman parte del derecho interno mexicano, simplemente se han citado a mayor abundamiento, para orientar el criterio que sustenta este Tribunal, como de la misma forma lo ha realizado la Suprema Corte de Justicia de la Nación en diversas ejecutorias. ${ }^{51}$

\section{REFLEXIONES FINALES Y ACOTACIONES ADICIONALES}

Las resoluciones anteriores establecen en términos generales una base para pensar que el Poder Judicial de la Federación está consciente de las obligaciones internacionales que tiene México y de la forma en que se puede incluir el derecho internacional dentro del sistema jurídico nacional. Esta primera afirmación se evidencia primordialmente al establecer a los tratados internacionales en un nivel jerárquico superior a las leyes federales, locales y generales con argumentos que se aproximan mucho a establecer un bloque de constitucionalidad. Igualmente la SCJN ha utilizado fuentes de derecho internacional como la costumbre internacional y las resoluciones de la asamblea para sustentar o reforzar sus argumentos y de esta manera las ha reconocido e integrado al sistema jurídico mexicano a pesar de que no están previstas expresamente como fuentes de derecho en el ámbito nacional.

Sin embargo, como se advertía en la introducción, no se trata de casos en los cuales se interprete o aplique un tratado internacional, lo cual no sería otra cosa que acatar el mandato del artículo 133 constitucional, sino una verdadera ampliación de su significado mediante la incorporación de otras fuentes de derecho internacional. A su vez, el alcance de esta afirmación debe quedar acotado, pues no se puede expandir esta afirmación más allá de las fuentes mencionadas por la SCJN. En otras palabras, la argumentación de la SCJN no puede hacerse extensiva a los principios generales de derecho, las obras de los publicistas o las resoluciones judiciales; sin embargo, no habría obstáculo para que se hiciera este reconocimiento en resoluciones posteriores. 
Es importante destacar que en el caso de los husos horarios, la SCJN aplicó las conclusiones derivadas de la Conferencia de París como normas de derecho consuetudinario internacional; sin embargo, muchas de las normas derivadas de conferencias similares se toman como normas jurídicas en formación. ${ }^{52}$ De tal forma que esta resolución no puede llevarse al extremo de incluir estas incipientes normas jurídicas.

En conclusión, lo relevante de este criterio es que la SCJN estableció que es posible fundar un acto de autoridad en la costumbre internacional; inclusive que existe una obligación de regular dichas normas jurídicas, como lo hizo el presidente con las conclusiones de la Conferencia de París.

En el ámbito nacional el caso de la efedrina ilustra una posición más dura en cuanto a la incorporación del derecho internacional, pues al aceptar la posibilidad de que los tipos penales contemplen ciertos elementos en tratados internacionales, se trata de una forma de romper con la postura tradicional que señalaba que los tipos penales deberían estar contemplados exclusivamente en leyes emanadas del órgano legislativo. Cabe aclarar que aun cuando en el apartado relativo se especula en torno a los alcances que esta determinación pudiera tener, en función de lo dispuesto en el artículo 6o. del Código Penal Federal, esta interpretación se limita (de momento) a la inclusión de elementos típicos en tratados internacionales; no del tipo penal en su totalidad.

En los TCC se pueden encontrar otras resoluciones de gran interés. En principio está la afirmación de que todas las normas jurídicas deben interpretarse de conformidad con el principio pro homine y maximización de los derechos humanos; pero además, establecer la obligación de que las autoridades deben seguir este principio en la aplicación de todas sus determinaciones.

Esta interpretación a favor de los derechos humanos está íntimamente relacionada con el caso de vagancia y malvivencia, en donde también se hizo uso de los derechos humanos. En esta oportunidad no se estableció una regla genérica en torno a la interpretación de los actos de autoridad, sino que se estableció la posibilidad (y ejemplo para otros tribunales) de que los derechos humanos sean una fuente de interpretación y de concreción de conceptos y definiciones. Al analizar ambas posturas en su conjunto, se llega a la conclusión de que para hacer una interpretación 
pro homine y de maximización de los derechos humanos de alguna disposición, se debe definir de conformidad con los criterios utilizados por los instrumentos y criterios en materia de derechos humanos. En definitiva, el uso de conceptos derivados del derecho internacional de los derechos humanos es una forma de aplicar el principio pro homine y de maximización de los derechos humanos.

A su vez, esta afirmación está estrechamente ligada a los criterios emanados de las resoluciones de la Corte Interamericana de Derechos Humanos como se desprende del asunto relativo a la asistencia consular, pues en las resoluciones de este órgano jurisdiccional se pueden encontrar criterios de interpretación pro homine y de maximización de los derechos humanos, así como la precisión de conceptos. Ambos son herramientas útiles para darle contenido a las normas de derecho interno.

Este caso, además, es otro ejemplo de cómo los tribunales nacionales interpretan directamente el derecho internacional y proporcionan elementos para que otras instancias judiciales en el extranjero adopten criterios similares armonizando así los alcances del derecho internacional. En otras palabras, la resolución del tribunal colegiado, con una difusión apropiada, puede contribuir al desarrollo y delimitación del derecho de asistencia consular. Adicionalmente, es un ejemplo de un tribunal nacional aplicando un derecho que si bien ha sido reconocido en el ámbito internacional, su aplicación en la esfera nacional no cuenta con muchos antecedentes. En particular son importantes sus contribuciones en los casos en los cuales el proceso inicia a partir de una extradición, supuesto que no había sido tratado anteriormente.

Por otro lado, no se debe perder de vista que estos criterios, aunque demuestran posturas progresistas en la interpretación y aplicación del derecho internacional en el ámbito nacional (o por lo menos federal), no pueden ser tomados como posturas generalizadas en el Poder Judicial de la Federación, ya que son muchos más los casos en los cuales no se adopta una postura compatible con el derecho internacional.

De tal forma que estos criterios deben difundirse, para que sean adoptados y seguidos por otros tribunales federales y estatales, de tal suerte que se generalice la homologación entre el derecho internacional y el derecho interno, de conformidad con las posturas más modernas sobre la relación entre ambos cuerpos normativos. 